\title{
O PREENCHIMENTO DO SUJEITO PRONOMINAL EM TEXTOS ESCRITOS DE ALUNOS ADOLESCENTES DE FLORIANÓPOLIS
}

\section{PRONOMINAL SUBJECT REALIZATION IN TEXTS WRITTEN BY ADOLESCENT STUDENTS OF FLORIANÓPOLIS}

\author{
Christiane Maria Nunes de Souza \\ Programa de Pós-graduação em Lingüística - UFSC/CNPq \\ Ana Kelly Borba da Silva Brustolin \\ Faculdade Borges de Mendonça e Prefeitura Municipal de Florianópolis \\ Patricia Floriani Sachet \\ Graduação em Letras - UFSC \\ Izete Lehmkuhl Coelho \\ Universidade Federal de Santa Catarina - CNPq
}

\begin{abstract}
Resumo
Este trabalho tem como propósito investigar os resultados da distribuição do número de sujeitos nulos e sujeitos realizados (ambos pronominais) em amostras de textos escritos de alunos adolescentes de uma escola pública de Florianópolis, considerando o controle das variáveis: 'pessoa do discurso', 'forma de realização do pronome', 'concordância verbal', 'sexo/gênero' e 'escolaridade'. Os resultados estatísticos atestam estudos anteriores no sentido de mostrar uma tendência ao preenchimento do sujeito pronominal, motivada tanto por fatores linguísticos ('formas de realização do pronome' e 'concordância') como extralinguísticos ('escolaridade').
\end{abstract}

Palavras-chave: parâmetro do sujeito nulo; pronomes pessoais; dados de escrita.

\begin{abstract}
This paper investigates the results of distribution in the number of null subjects and overt subjects (both pronominal) in samples of texts written by adolescents attending a public school in Florianópolis, Santa Catarina, Brazil. The control variables are 'grammatical person', 'pronoun realization mode', 'subject-verb agreement', 'sex/ gender', and 'education level'. Statistical results confirm prior studies which show a tendency for the fulfilling of pronominal subjetcs, motivated both by linguistic factors ('pronoun realization mode' and 'verb agreement') and extralinguistic factors ('education level').
\end{abstract}

Keywords: null subject parameter; personal pronouns; writing data.

\section{INTRODUÇÃO}

Estudos sociolinguísticos têm indicado que a língua portuguesa falada no Brasil apresenta, cada vez mais, sentenças de sujeito pronominal preenchido (cf. DUARTE, 1993, 1995; 
COSTA, 2003; PAREDES DA SILVA, 2003; NUNES DE SOUZA; SACHET, 2008, entre outros). Algumas pesquisas já são realizadas não mais buscando verificar se as frequências de preenchimento do sujeito pronominal estão mudando, mas sim já partindo do pressuposto de que o português brasileiro (doravante $\mathrm{PB}$ ) está em fase de transição de língua marcada positivamente para o parâmetro pro-drop para uma língua não pro-drop (é o caso de DUARTE, 2003).

Com esse pressuposto em mente e amparadas na Teoria da Variação e Mudança (cf. WEINREICH; LABOV; HERZOG, 1968; LABOV, 1972), a qual considera a língua um sistema heterogêneo, regido por, além de regras categóricas, regras variáveis condicionadas, em geral, por fatores internos e externos, visamos a alcançar os seguintes objetivos: (i) identificar que fatores condicionadores internos e externos, dentre aqueles que controlamos, estariam atuando no favorecimento ou na inibição do preenchimento do sujeito pronominal na escrita de alunos do Ensino Fundamental de uma escola pública de Florianópolis; e (ii) investigar qual a correlação entre a frequência de preenchimento do sujeito pronominal e os grupos de fatores 'formas pronominais' e 'escolaridade'.

Utilizando uma amostra formada de textos escritos de alunos do terceiro e quarto ciclos do Ensino Fundamental, queremos responder às seguintes questões: (i) que sujeitos pronominais são mais preenchidos e nulos na escrita de alunos do Ensino Fundamental?; (ii) o fenômeno variável em questão é sensível às variáveis linguísticas e extralinguísticas controladas?; e (iii) o que revelam os resultados estatísticos relacionados a cada série escolar?

Partimos da hipótese de que o sujeito pronominal preenchido seja condicionado pelos pronomes de segunda e terceira pessoa do discurso, especialmente aqueles que acompanham verbos de terceira pessoa do singular (a gente, você, ele) ou do plural (vocês, eles). Com relação à 'concordância verbal', esperamos que pronomes preenchidos levem a menores índices de concordância verbal canônica e pronomes nulos à manutenção das marcas morfêmicas de concordância nos verbos. No que se refere ao grupo de fatores 'escolaridade', acreditamos que alunos da quinta série usem mais sujeitos pronominais preenchidos do que os da oitava série. Avaliamos que os alunos da oitava série possam fazer uso de uma linguagem mais monitorada, evitando repetição de pronomes.

Feita esta breve introdução, passamos à organização do artigo. Na segunda seção, serão apresentadas notas sobre o parâmetro do sujeito nulo, com o propósito de delimitar nosso objeto de estudo. Na próxima seção, detalharemos a metodologia utilizada nesta pesquisa. Na seção 4, serão expostos e discutidos os resultados estatísticos. Por fim, serão feitas algumas considerações a título de conclusão.

\section{NOTAS SOBRE O PARÂMETRO DO SUJEITO NULO}

Nosso objeto de estudo - a variação do preenchimento do sujeito pronominal - se enquadra em um dos parâmetros postulados na literatura gerativa, mais especificamente no modelo de Princípios e Parâmetros (cf. CHOMSKY, 1981; 1986): o parâmetro do sujeito nulo, 
conhecido também como parâmetro pro-drop. Foi oficialmente proposto por Chomsky (1981), como passo inicial da distinção das línguas com relação à possibilidade de apresentarem ou não um sujeito nulo.

O parâmetro do sujeito nulo consiste na habilidade ou não habilidade de uma língua exibir sintagmas nominais nulos na posição de sujeito. Após vários estudos interlinguísticos ${ }^{1}$, Chomsky (1981) propõe o seguinte conjunto de propriedades como características de línguas fixadas no valor positivo desse parâmetro:
a) sujeito nulo;
b) inversão livre do sujeito em orações principais;
c) movimento QU- longo do sujeito;
d) pronome lembrete nulo em orações encaixadas;
e) aparente violação do filtro 'that t' ${ }^{2}$

De acordo com esse parâmetro, uma língua marcada no valor positivo para o sujeito nulo admite, entre outras coisas, uma categoria vazia na posição de especificador de IP (Inflectional Phrase) e a ordem verbo-sujeito, como o italiano, por exemplo. Uma língua marcada pelo valor negativo, ao contrário, não licencia uma categoria vazia na posição sujeito, nem a ordem verbo-sujeito, como o inglês, por exemplo.

O português faz parte do grupo de línguas que tem a capacidade de licenciar sujeitos nulos. Entretanto, estudos mostram que o uso explícito do pronome tem sido cada vez mais frequente no português do Brasil (PB), diferentemente do português europeu (PE). Como já dissemos, alguns trabalhos atestam uma mudança paramétrica, ou pelo menos uma situação de variação no PB: de uma língua de sujeito nulo para uma língua de sujeito lexicalmente preenchido. Merecem destaque, dentre eles, os trabalhos pioneiros de Duarte $(1993,1995)$. Paralelamente a esses estudos, os trabalhos de Berlinck (1988; 1995) e de Coelho (2000, 2006) atestam que o PB está perdendo a propriedade de inversão da ordem verbo-sujeito em construções pluriargumentais e, cada vez mais, pode ser identificado como uma língua de ordem sujeito-verbo-objeto (SVO) enrijecida, como o inglês.

Com relação à propriedade de sujeito nulo, os trabalhos supracitados mostram que no PB há uma correlação entre a mudança que se verifica na passagem de sujeito nulo para sujeito preenchido e a mudança que se observa no paradigma pronominal. Em seu trabalho de 1993, Duarte aponta que, no período em que as formas tu e vós coexistiam com você/vocês (estas como formas adicionais de tratamento) o sujeito nulo predominava sobre o

\footnotetext{
${ }^{1}$ Chomsky (1981) e seus seguidores investigam diferentes línguas humanas com o propósito de entender princípios comuns a todas as línguas e parâmetros, isto é, variação interlínguas. O sujeito nulo se constitui um desses parâmetros.

${ }^{2}$ Segundo Figueiredo Silva (1996, p. 31), o filtro 'that t' impede o movimento do sujeito por cima de um complementizador lexicalmente realizado. O italiano parece não ser sensível a esse filtro, já o francês o é, como os exemplos retirados da autora podem mostrar, a seguir:
}

(i) * Qui ${ }_{i}$ tu penses que $t_{i}$ partira?

(ii) $\mathrm{Chi}_{\mathrm{i}}$ credi che $\mathrm{t}_{\mathrm{i}}$ partirà? 
preenchido (peças de 1845, 1882 e 1918). Quando os pronomes tu e vós começam a desaparecer, sendo substituídos pelos pronomes pessoais você/vocês, há um considerável decréscimo do percentual de sujeitos nulos de segunda pessoa: de 69\% para 25\% (peças de 1918 e de 1937, respectivamente). Quanto à primeira pessoa do plural, os resultados da autora mostram que, dos três primeiros períodos analisados (1845, 1882 e 1918) para o último (1992), o percentual de nulos cai de $100 \%$ para $7 \%$, um uso quase categórico de sujeito preenchido. Essa queda também coincide com a gramaticalização da forma nominal a gente em pronome de primeira pessoa do plural, o qual passa a coocorrer e a concorrer com a forma nós ${ }^{3}$.

Duarte (1993) associa essa mudança em curso à entrada das formas pronominais você/vocês e a gente no paradigma pronominal, que se combinam com verbos de terceira pessoa (singular/plural), o que leva à simplificação do paradigma flexional. De acordo com a autora, a escrita formal ainda conserva um paradigma funcionalmente rico, ao contrário do que ocorre com a fala espontânea. Por essa razão, o PB falado estaria perdendo a possibilidade de recuperar o referente através do elemento de concordância, dada, em geral, por desinências distintivas.

Uma outra diferença significativa entre falantes que usam sujeito pronominal preenchido ou nulo diz respeito à faixa etária. Segundo Duarte (1995), informantes mais velhos optam tanto pelo sujeito nulo quanto pelo pleno, enquanto que os mais jovens dão preferência ao preenchimento. Isso ocorre provavelmente porque a língua a que os mais jovens estão expostos tem uma frequência de uso mais significativa de sujeitos preenchidos do que nulos, diferentemente da língua a que falantes - hoje de 70 anos - estavam expostos na adolescência (há 55 anos).

Trabalhos como os de Costa (2003) e Brustolin (2009) atestam os resultados de Duarte (2005), com relação às diferenças entre linguagem falada e escrita e com relação à faixa etária. Jovens alunos de diferentes escolas de Florianópolis usam mais sujeitos preenchidos que nulos tanto na linguagem falada quanto na escrita.

A correlação entre preenchimento do sujeito e forma de realização do pronome, em dados de linguagem escrita de alunos adolescentes, será nosso principal foco de atenção neste trabalho.

\section{METODOLOGIA}

A metodologia deste trabalho seguiu, de certa forma, os passos da sociolinguística quantitativa laboviana, por contar com uma amostra de dados de escrita sistemática, o mais próxima possível da informalidade, e por controlar grupos de fatores (internos e externos)

\footnotetext{
${ }^{3}$ Brustolin (2009), ao investigar as formas variáveis de realização do pronome de primeira pessoa do plural nós e a gente, considerando como uma de suas variáveis o 'preenchimento do sujeito', constatou que há predominância de a gente no que se refere ao sujeito preenchido, com peso relativo de 0,89 , enquanto o pronome nós aparece preferencialmente em contextos de não realização do sujeito (ou de sujeito nulo).
} 
que estariam motivando a variação encontrada. As subseções seguintes descrevem esses passos metodológicos.

\subsection{Amostra}

A amostra utilizada nesta pesquisa é composta por textos escritos de alunos do terceiro e quarto ciclos do Ensino Fundamental ( $5^{\mathrm{a}}$ à $8^{\mathrm{a}}$ série) de uma escola da Rede Estadual de Florianópolis, situada na região central da cidade, e foi coletada ao longo do ano de 2008. A coleta dessa amostra se constituiu como uma das etapas do projeto de extensão Variação linguística e ensino de gramática nas escolas do Ensino Fundamental: um estudo do paradigma pronominal, coordenado pela profa. Dra. Izete Lehmkuhl Coelho. O Projeto contou com a cooperação voluntária de quatro alunos do Curso de Graduação em Letras e de duas alunas da Pós-graduação em Linguística da Universidade Federal de Santa Catarina.

A coleta da amostra que compõe o Projeto levou em conta os seguintes critérios: foi pedido aos alunos do Ensino Fundamental de quatro escolas públicas estaduais florianopolitanas que escrevessem uma história baseada em uma experiência pessoal. Os textos foram recolhidos e, posteriormente, os pesquisadores voltaram às escolas e solicitaram aos alunos que contassem a mesma história, mas dessa vez oralmente. O objetivo do Projeto consistiu em estabelecer comparações entre a fala e a escrita dos alunos, com vistas a analisar casos de variação diamésica referentes ao uso dos pronomes. Por ora, para este artigo serão utilizados apenas dados de escrita de alunos de uma das quatro escolas envolvidas no Projeto.

\subsection{Envelope de variação}

Os dados coletados para este trabalho constituem-se de sentenças declarativas com sujeitos pronominais anafóricos ou dêiticos preenchidos e nulos. Foram excluídos da análise sujeitos pronominais indeterminados. Após a coleta, os dados foram categorizados de acordo com as variáveis descritas abaixo.

\subsubsection{Variável dependente}

A variável dependente investigada neste trabalho é o preenchimento ou não do sujeito pronominal, verificado em sentenças declarativas da amostra utilizada. Essa variável se constitui de duas variantes: pronome preenchido e pronome nulo, como ilustrado em (1) e (2), respectivamente.

(1) Eu fiquei furiosa porque faltava um dia para começar minhas aulas. (5 série, $\mathrm{F}^{4}, 11$ anos, inf. 25)

\footnotetext{
${ }^{4} \mathrm{Na}$ identificação da estratificação dos informantes, $\mathrm{F}=$ sexo/ gênero feminino e $\mathrm{M}=$ sexo/ gênero masculino.
} 
(2) Todos os finais de semana $\varnothing$ vou para a casa de minha vó. (5ª série, F, 11 anos, inf. 27)

\subsubsection{Variáveis independentes}

As variáveis linguísticas e extralinguísticas, apresentadas a seguir, foram controladas com o propósito de observar seu condicionamento no preenchimento (ou não) do sujeito pronominal.

\subsubsection{Variável 'pessoa do discurso'}

Foram considerados dados com pronomes sujeitos tanto do singular como do plural relativos às 1,2 e $3^{\mathrm{a}}$ pessoas do discurso, nulos e preenchidos, como os exemplificados a seguir, respectivamente.

(3) Eu tive que pular na lage da visinha.(5ª́rie, M, 10 anos, inf. 26)

(4) Você tá bem lindo. (6ª série, F, 12 anos, inf. 30)

(5) Eles sempre me levam. (5 série, F, 11 anos, inf. 3)

\subsubsection{Variável 'formas de realização do pronome pessoal'}

Esse grupo teve como fatores os pronomes pessoais eu, tu, você, ele/ela, nós, a gente, vocês e eles/elas, em posição de sujeito da sentença, nulos e preenchidos. Abaixo, dados encontrados com essas formas de realização, respectivamente.

(6) $\varnothing$ Vou contar sobre um dia... (5 série, M, 11 anos, inf. 2)

(7) Mais tu é troxa demais. (8a série, M, 14 anos, inf.100)

(8) Você vai estar sempre no meu coração. (6 $6^{a}$ série, F, 16 anos, inf. 45)

(9) Ela sempre me leva pra sair. ( $5^{\mathrm{a}}$ série, F, 11 anos, inf. 3)

(10) Nóis pedimos quatro reais de pão doce. (6 $6^{\mathrm{a}}$ série, F, 12 anos, inf. 32)

(11) E a gente ficou lá quase um mês durante as férias. ( 6ª série, F, 11 anos, inf. 34)

(12) Não porque vocês vão me afogar. (6 $6^{\mathrm{a}}$ série, F, 12 anos, inf. 41)

(13) Eles empataram em 2-2. (5ª série, M, 12 anos, inf. 6)

\subsubsection{Variável ‘concordância verbal’}

Foram considerados dados com concordância canônica e sem concordância canônica. Abaixo, seguem dados desses dois tipos, respectivamente. 
(14) Eu nunca mais esquecerei essa história. (7ª série, F, 12 anos, inf. 77)

(15) Quando a gente távamos indo embora rolou o primeiro beijo.(7ª́rie, F, 12 anos, inf.69)

\subsubsection{Variável 'escolaridade’}

O controle foi realizado levando-se em conta informantes da $5^{\mathrm{a}}, 6^{\mathrm{a}}$, $7^{\mathrm{a}}$ e $8^{\mathrm{a}}$ série do Ensino Fundamental.

\subsubsection{Variável ‘sexo/gênero’}

Foram levados em consideração, para esse grupo, os fatores ‘masculino’ e ‘feminino’.

\section{DISCUSSÃO DOS RESULTADOS}

Após a coleta de todos os sujeitos pronominais definidos da amostra utilizada - 787 ocorrências - os dados foram categorizados e submetidos à análise estatística unidimensional e multidimensional do Goldvarb2001 (cf. ROBINSON; LAWRENCE; TAGLIAMONTE, 2001). No conjunto dos dados, foram encontrados 292 casos de sujeitos pronominais nulos e 495 preenchidos, conforme mostra, em termos de frequência, o gráfico 1 , a seguir.

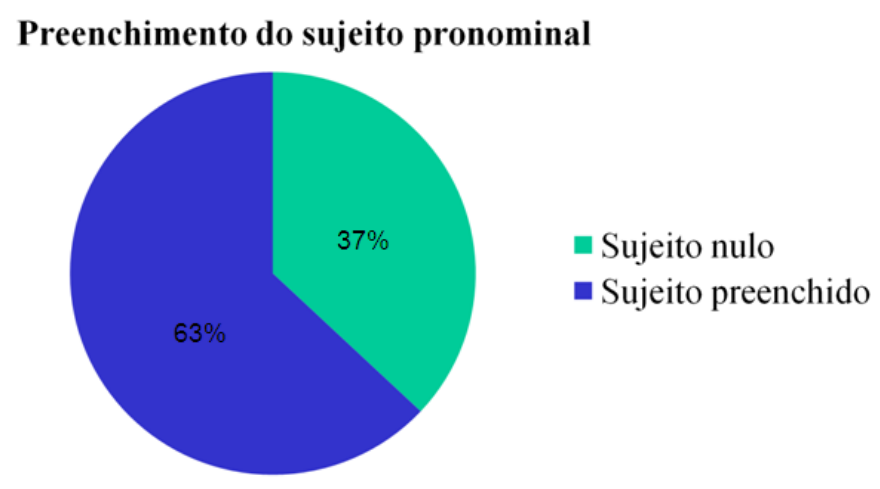

GRÁFICO 1: Resultado geral para a variável dependente 'preenchimento do sujeito pronominal'.

Os resultados gerais corroboram os números a que chegaram estudos anteriores e indicam, especialmente, uma preferência pelo preenchimento do sujeito pronominal na escrita. A considerável frequência de sujeitos pronominais preenchidos encontrados nesta pesquisa sugere que a mudança por que tem passado o $\mathrm{PB}$ no que diz respeito ao parâmetro pro-drop não está restrita somente à fala e já se encontra em estágios mais avançados.

As hipóteses aventadas na seção 1 foram parcialmente atestadas e as variáveis selecionadas como significativas pelo pacote estatístico Goldvarb2001 foram, em ordem de importância: 
1) Forma de realização do pronome

2) Escolaridade

3) Concordância verbal

\subsection{Forma de realização do pronome}

Os resultados para essa variável encontram-se na Tabela 1, a seguir.

TABELA 1: Resultados de preenchimento do sujeito pronominal, segundo a variável 'forma de realização do pronome'.

\begin{tabular}{|c|c|c|c|}
\hline Forma de realização do pronome $e^{5}$ & Apl/Total & $\%$ & $P R$ \\
\hline $\mathrm{Eu}$ & $256 / 425$ & 60 & 0,43 \\
\hline Nós & $74 / 165$ & 45 & 0,31 \\
\hline A gente & $62 / 71$ & 87 & 0,87 \\
\hline Você/vocês ${ }^{6}$ & $7 / 8$ & 88 & 0,85 \\
\hline Ele(a)/Eles(as) & 96/119 & 81 & 0,70 \\
\hline Total & $495 / 787$ & 63 & \\
\hline
\end{tabular}

Pelos números da Tabela 1, é possível perceber que, como imaginávamos, os pronomes que fazem concordância canônica de $3^{\mathrm{a}}$ pessoa (a gente, você/ vocês e ele(a)/ eles(as)) foram os que mais apresentaram sujeito preenchido, com especial destaque para a gente e você/vocês ( $\mathrm{PR}=0,87$ e 0,85, respectivamente). Possivelmente, o maior índice de preenchimento decorreu da necessidade de retenção do pronome para evitar ambiguidade, dada a impossibilidade de recuperar o referente por meio do elemento de concordância, nesses casos, por desinências não distintivas. Em se tratando dos pronomes eu e nós, a retenção do pronome não é necessária, pois geralmente eles se combinam com marcas morfêmicas verbais particulares.

Quando reunimos as formas de representação considerando a pessoa do discurso, o que se percebe é que a primeira pessoa se mostra como pouco favorecedora do sujeito preenchido, como a Tabela 2 ilustra.

\footnotetext{
${ }^{5}$ Após a primeira rodada do Goldvarb, os pronomes de segunda pessoa tu, você/vocês foram amalgamados por apresentarem knockout e serem em número muito reduzido de ocorrências (apenas 8 dados). O mesmo procedimento foi feito para os pronomes de terceira pessoa ele/eles, por mostrarem comportamento indistinto.

${ }^{6}$ Dos pronomes de segunda pessoa encontrados em nossa amostra, 7 são da forma você/vocês e apenas 1 ocorrência é do pronome tu.
} 
TABELA 2: Resultados de preenchimento do sujeito pronominal, segundo a variável 'pessoa do discurso'.

\begin{tabular}{l|ll}
\hline Variável pessoa do discurso & Apl/Total & \% \\
\hline $1^{\text {a }}$ Pessoa & $391 / 660$ & 59 \\
\hline $2^{\text {a. }}$ Pessoa & $7 / 8$ & 88 \\
\hline $3^{\text {a }}$ Pessoa & $97 / 119$ & 82 \\
\hline Total & $\mathbf{4 9 5 / 7 8 7}$ & $\mathbf{6 3}$ \\
\hline
\end{tabular}

Esse resultado não segue a mesma curva percentual de Duarte (1993). Para a autora, os pronomes de primeira pessoa e os de segunda são condicionadores fortes da retenção do sujeito, enquanto os de terceira se mostram inibidores. Um aspecto pode nos ajudar a entender essa diferença. Categoricamente, os pronomes de terceira pessoa encontrados em nossa amostra são de sujeito [+animado] $]^{7}$. Ora, trabalhos indicam que sujeitos de terceira pessoa marcados com traço [+animado] tendem a reter mais o sujeito, enquanto sujeitos [animado] tendem a preferir a forma nula. Nesse caso, nossos resultados vêm reforçar a estreita relação existente entre traço [+animado] e preenchimento do sujeito.

\subsection{Escolaridade}

Na Tabela 3, a seguir, são apresentados os resultados para essa variável.

TABELA 3: Resultados de preenchimento do sujeito pronominal, segundo a variável 'escolaridade'.

\begin{tabular}{l|lll}
\hline Escolaridade & Apl/Total & \% & PR \\
\hline $5^{a}$. série & $184 / 255$ & 72 & 0,60 \\
\hline $6^{\text {a. série }}$ & $148 / 242$ & 61 & 0,46 \\
\hline $7^{\text {a. }}$ série & $56 / 95$ & 59 & 0,44 \\
\hline $8^{\text {a. }}$ série & $107 / 195$ & 55 & 0,45 \\
\hline Total & $\mathbf{4 9 5 / 7 8 7}$ & $\mathbf{6 3}$ & \\
\hline
\end{tabular}

Nota-se que os alunos das séries mais baixas preenchem mais o sujeito pronominal, o que pode ser um indicativo de que, na escola, ainda seja aprendido o princípio "evite o pronome" (cf. DUARTE, 1995). Portanto, quanto mais tempo na escola, menos o aluno preenche o sujeito pronominal, corroborando também resultados estatísticos de Costa (2003) e de Brustolin (2009).

Ao cruzarmos esses resultados com as formas de realização do sujeito pronominal (cf. Tabela 4), percebemos que a diferença entre os alunos se mostra principalmente na primeira pessoa do singular (eu), em que alunos da $5^{\mathrm{a}}$. série usam $74 \%$ de sujeito preenchido. Quanto às formas de primeira pessoa do plural (nós e a gente), os resultados atestam um favorecimento do preenchimento para o pronome a gente e um desfavorecimento para o pronome nós, em todas as séries. 
Com relação aos pronomes de terceira pessoa (ele(s)), categoricamente marcados com traço [+animado], o elevado percentual de favorecimento à retenção do pronome indica uma preferência pelo pronome preenchido em todas as séries, à semelhança do comportamento do pronome a gente.

TABELA 4: Cruzamento entre as variáveis 'formas de realização do pronome' e 'escolaridade'

\begin{tabular}{c|c|c|c|c|c}
\hline $\begin{array}{c}\text { Escolaridade/ } \\
\text { Formas de } \\
\text { realização do } \\
\text { pronome }\end{array}$ & $\boldsymbol{E u}$ & Você(s) & Nós & A gente & Ele(s) \\
\hline $5^{\mathrm{a}}$. série & $120 / 162$ & $0 / 1$ & $11 / 33$ & $25 / 26$ & $28 / 33$ \\
& $74 \%$ & $0 \%$ & $33 \%$ & $96 \%$ & $85 \%$ \\
\hline $6^{\mathrm{a}}$. série & $58 / 106$ & $5 / 5$ & $26 / 58$ & $22 / 28$ & $37 / 45$ \\
& $55 \%$ & $100 \%$ & $45 \%$ & $79 \%$ & $82 \%$ \\
\hline $7^{\mathrm{a}}$. série & $28 / 53$ & $1 / 1$ & $9 / 16$ & $9 / 11$ & $9 / 14$ \\
& $53 \%$ & $100 \%$ & $56 \%$ & $82 \%$ & $64 \%$ \\
\hline $8^{\mathrm{a}}$. série & $50 / 104$ & $1 / 1$ & $28 / 58$ & $6 / 6$ & $22 / 26$ \\
& $48 \%$ & $100 \%$ & $48 \%$ & $100 \%$ & $85 \%$ \\
\hline
\end{tabular}

\subsection{Concordância verbal}

Os números encontrados para essa variável são apresentados na Tabela 5, a seguir.

TABELA 5: Resultados de preenchimento do sujeito pronominal, segundo a variável 'concordância verbal'

\begin{tabular}{l|lll}
\hline Concordância verbal & Apl/Total & \% & $\mathbf{P R}^{9}$ \\
\hline Concorda & $479 / 762$ & 63 & 0,51 \\
\hline Não concorda & $16 / 25$ & 64 & 0,18 \\
\hline Total & $\mathbf{4 9 5 / 7 8 7}$ & $\mathbf{6 3}$ & \\
\hline
\end{tabular}

Destaca-se que, diferentemente do que havíamos previsto, a não concordância canônica é favorecedora do sujeito nulo (com peso relativo de apenas 0,18 para o sujeito preenchido). Uma possível explicação para esse condicionamento é que a não concordância está relacionada, em geral, aos pronomes a gente. O que se observa nesse caso é que a sentença começa com a retenção do pronome a gente, combinado com verbo na primeira pessoa do plural, e segue com o pronome nulo mantendo o paralelismo no morfema do verbo, como os exemplos a seguir ilustram:

\footnotetext{
${ }^{8}$ Note-se que, das 08 ocorrências do pronome de segunda pessoa (singular e plural), a maioria delas foi encontrada em textos de alunos da $6^{a}$. série (05/08), o que nos impede de fazer qualquer consideração.

${ }^{9}$ Vale registrar que o peso relativo desta variável 'concordância verbal' se alterou de 0,50 (para concordância) e .51 (para não concordância) com sujeito preenchido para 0,51 e 0,18, respectivamente, no momento da interação dessa variável com ‘forma de realização do sujeito'.
} 
(16) Depois, agente saímos do shopping e $\varnothing$ fomos no parque de diversões (5a série, F, 10 anos, inf. 14)

(17) A gente fomos pra praia. $\varnothing$ Voltamos só a noite e o resto dos dias $\varnothing$ ficamos brincando (6 $6^{\text {a }}$ série, F, 11 anos, inf. 33)

(18) Da $8^{\mathrm{a}}$ a gente perdeu, a gente ficamos em $2^{\circ}$ lugar (6 ${ }^{\mathrm{a}}$ série, F, 12 anos, inf. 57)

(19) Agente se arrumamos e Ø fomos (7ª série, M, 13 anos, inf. 68)

Das 16 ocorrências de não concordância com sujeitos preenchidos, 11 estão acompanhadas do pronome a gente, como os exemplos de (16) a (19) ilustram. Esse fenômeno é conhecido na literatura como concordância semântica. Em seu estudo, Brustolin (2009), cruzou as variáveis sujeito preenchido e marca morfêmica e obteve $96 \%$ para uso de sujeito preenchido a gente $\varnothing$, contra $4 \%$ de nós $\varnothing$ e $11 \%$ de a gente -mos na posição de sujeito preenchido contra $89 \%$ de nós -mos. A autora diz que um aspecto evidenciado no PB se refere ao fato de o pronome a gente estar associado semanticamente com o referente no plural, ou seja, podemos encontrar na língua exemplos de fala como: a gente dançamos, a gente fomos, entre outros, o que colabora para assinalar o pronome a gente como um pronome pessoal, visto que o falante o emprega associando-o ao "eu" (pessoa que fala) e mais outra(s) pessoas.

As 05 ocorrências de não concordância restantes se distribuem entre os pronomes, $e u^{10}(02$ ocorrências), nós (exemplos (20) e (21)) e tu (exemplo (22)). Só essas três últimas ocorrências de sujeito preenchido sem marcação de concordância é que atestariam a nossa hipótese, segundo a qual pronomes preenchidos deveriam levar a menores índices de concordância verbal canônica para se evitar redundância de marcas. Vale ressaltar, ainda, que a não marcação diminui na medida em que se aumenta a escolaridade: $64 \%$ das ocorrências sem marcação de concordância canônica aparecem em textos de alunos das $5^{\text {a }}$. e $6^{\text {a }}$. séries, $20 \%$ na de $7^{\text {a }}$ e $16 \%$ na de $8^{\text {a }}$. Esses resultados confirmam trabalhos sobre os efeitos da escolaridade na marcação da concordância verbal no PB (cf. MONGUILHOTT 2001, 2009).

(20) Nós da quinta série estava jogando e ganhamo ( $5^{\mathrm{a}}$ série, $\mathrm{M}, 12$ anos, inf. 11)

(21) Nós tava andando de Bike ( $8^{\mathrm{a}}$ série, $\mathrm{M}, 13$ anos, inf. 101)

(22) Mais tu é troxa demais (8a série, M, 14 anos, inf. 100)

Com relação às 09 ocorrências de não concordância com o sujeito nulo, percebemos que todas se apresentam em contextos em que a forma a gente foi citada na sentença principal.

\footnotetext{
${ }^{10}$ Acreditamos que os dois casos de não concordância com o pronome eu devem ter sido por problema de letramento ou troca de letra. Ambos os exemplos foram encontrados no texto de um mesmo informante da $5^{\mathrm{a}}$ série, do sexo/ gênero masculino:
}

- As vezes eu não albedeça a minhas professora

- Eu ganha as coisas da professora 


\section{CONSIDERAÇÕES FINAIS}

Pode-se notar que o preenchimento do sujeito pronominal parece ser motivado tanto por fatores linguísticos ('formas de realização do pronome' e 'concordância verbal') como extralinguísticos ('escolaridade’). A forma de realização do pronome se revelou significativa possivelmente porque o PB está perdendo a possibilidade de recuperar o referente através do elemento de concordância e por conta da necessidade de explicitação do sujeito para se evitar a ambiguidade - necessidade decorrente da entrada dos pronomes $a$ gente e você(s) no paradigma pronominal do português (cf. DUARTE, 1995). O grupo de fatores linguísticos 'concordância verbal' também se mostrou significativo revelando, em especial, o comportamento peculiar do pronome a gente que, ao permanecer retido, combina ora com verbo na terceira pessoa do singular (82\%), ora com verbo na primeira pessoa do plural (18\%) e, ao permanecer nulo, combina categoricamente com verbo na terceira pessoa do singular (100\%). Já os resultados para a variável extralinguística 'escolaridade' parecem indicar que o papel da escola nessa mudança é refreá-la - pois, quanto mais escolarizado o informante, menor o número de sujeitos pronominais preenchidos na escrita.

De maneira geral, nosso trabalho trouxe mais uma contribuição para o estudo desse objeto, apresentando percentuais e pesos relativos que corroboram o que outros autores vêm constatando: o Português do Brasil está em fase de transição de uma língua pro-drop para uma língua não pro-drop.

\section{REFERÊNCIAS BIBLIOGRÁFICAS}

BERLINCK, R. A ordem V SN no português do Brasil: sincronia e diacronia. Campinas, 1988. Dissertação de Mestrado, UNICAMP.

BERLINCK, R. de A. La position du sujet en portugais: etude diachronique des variétés brésilienne et européene. Tese. Paris, 1995.

BRUSTOLIN, A. K. B. da S. Itinerário do uso e variação de nós e a gente em textos escritos e orais de alunos do ensino fundamental da rede pública de Florianópolis. 2009. Dissertação. Florianópolis: UFSC.

CHOMSKY, N. Lectures on government and binding. Dordrecht: Foris, 1981.

COSTA, S. O sujeito usado por crianças e adolescentes de Florianópolis: um estudo da ordem e do preenchimento. Dissertação. Florianópolis: UFSC, 2003.

COELHO, I. L. A ordem VDP em construções monoargumentais: uma restrição sintáticosemântica. 2000. Tese - Universidade Federal de Santa Catarina, Florianópolis. 
COELHO, I. L. Variação na sintaxe: estudo da ordem do sujeito no PB. RAMOS, J. (org.) Estudos Sociolingüísticos: quatro vértices do GT da ANPOLL. Belo Horizonte: FALE/UFMG, 2006, p. 84-99.

DUARTE, M. E. L. Do pronome nulo ao pronome pleno: a trajetória do sujeito no Português do Brasil. In: I. Roberts, M. A. Kato (orgs.). Português Brasileiro - Uma viagem diacrônica. Campinas: Editora da UNICAMP, 1993.

DUARTE, M. E. L. A perda do princípio "Evite Pronome” no Português Brasileiro. Tese. Campinas: UNICAMP, 1995.

DUARTE, M. E. L. O sujeito expletivo e as construções existenciais. In: RONCARATI, C.; ABRAÇADO, J. (orgs.). Português brasileiro: contato lingüístico, heterogeneidade e história. Rio de Janeiro: 7 letras, 2003.

FIGUEIREDO SILVA, M. C. A posição sujeito no português brasileiro. Frases finitas e infinitivas. Campinas, São Paulo: Editora da UNICAMP, 1996.

LABOV, W. Sociolinguistic Patterns. Philadelphia: University of Pennsylvania Press, 1972.

MENON, O. P. da S. A gente, eu, nós: sintomas de uma mudança em curso no português do Brasil? Anais do ELFE. Maceió: UFAL: 1995, p. 397-403.

MONGUILHOTT, I. de O. e S. Variação na concordância verbal de terceira pessoa do plural na fala dos florianopolitanos. Florianópolis, 2001. Dissertação, UFSC.

MONGUILHOTT, I. de O. e S. Estudo sincrônico e diacrônico da concordância verbal de terceira pessoa do plural no PB e no PE. Florianópolis, 2009. Tese, UFSC.

NARO, A. J.; GÖRSKI, E. M.; \& FERNANDES, E. (1999) Change without Change. Language Variation and Change. v. 11, $\mathrm{n}^{\circ}$ 2, New York, 1999, p. 197-211.

NUNES DE SOUZA, C. M.; SACHET, P. F. Um estudo sobre o preenchimento do sujeito pronominal na fala e na escrita de jovens de Florianópolis. Anais do CELSUL, 2008. Disponível em: http://www.celsul.org.br/Encontros/08/quanto_mais_eu_vivo.pdf

OMENA, N. P. A referência à primeira pessoa do discurso no plural. In: OLIVEIRA E SILVA, G. M.; SCHERRE, M. M. P. (orgs.) Padrões sociolingüísticos: estudos de fenômenos variáveis do português falado na cidade do Rio de Janeiro. Rio de Janeiro: Tempo Brasileiro, 1998, $2^{\mathrm{a}}$ ed. p.185-215.

PAREDES DA SILVA, V. L. Motivações funcionais no uso do sujeito pronominal: uma análise em tempo real. In: DUARTE, M. E. L.; PAIVA, M. C. (orgs.) Mudança lingüística em tempo real. Rio de Janeiro: Contracapa Livraria, 2003. 
ROBINSON, J.; LAWRENCE, H.; TAGLIAMONTE, S. (2001). GoldVarb: a multivariate analysis application for Windows. Department of Language an Linguistic Science, University of York. http://www.york.ac.uk/depts/lang/webstuff/golvarb/.

WEINREICH, U.; LABOV, W.; HERZOG, M. Empirical foundations for a theory of language change. In: LEHMAN; MALKIEL (Ed.) Directions for historical linguistics. Austin, University of Texas Press, 1968. 